\title{
KÜMEDUNGUN: TRAJETÓRIAS DE VIDA E A ESCRITA DE SI DE MULHERES POETAS MAPUCHE
}

\author{
MOLINA, Valentina Paz Bascur ${ }^{1}$
}

RESUMO: O presente artigo pretende apresentar as trajetórias de vida de três escritoras indígenas Mapuche, que têm se destacado no cenário literário chileno nas últimas décadas: Maribel Mora Curriao, Graciela Huinao e Rayen Kvyeh. Em diálogo com suas trajetórias de vida e obra, cabe questionar, como as mulheres poetas Mapuche criam os seus processos de subjetividade. A partir das suas narrativas de vida, considera-se que elas, através da criação literária, expressam formas de vida que se contrapõem às identidades impostas, sejam sociais, raciais, étnicas e de gênero. O objetivo é refletir acerca da construção das suas subjetividades através do ofício de escrever-se. As análises voltadas para as experiências e trajetórias de mulheres Mapuche podem contribuir com a desarticulação dos imaginários coloniais, racistas e sexistas. Narradoras, escritoras e poetas têm registrado os processos de luta para que as expressões artísticas do povo Mapuche sejam reconhecidas enquanto Literatura, já que as dinâmicas de exclusão estão assentadas nas raízes da colonização europeia, que valoriza a tradição escrita e o Espanhol como língua oficial, e que excluem as narrativas contra hegemônicas dos povos indígenas.

PALAVRAS-CHAVE: Mulheres Mapuche, Subjetividade, Literatura.

\section{KÜMEDUNGUN: LIFE TRAJECTORIES AND SELF-WRITING OF MAPUCHE WOMEN POETS}

ABSTRACT: The present article intends to submit the life trajectory of three indigenous Mapuche women writers that have highlighted on Chilean literary scene last decades: Maribel

\footnotetext{
${ }^{1}$ Mestre em Estudos Interdisciplinares sobre Mulheres, Gênero e Feminismo. Universidade Federal da Bahia. Contato: vale.bascur@gmail.com

Jangada | nr. 14, jul/dez, 2019 | ISSN 2317-4722 
Mora Curriao, Graciela Huinao and Rayen Kvyeh. From a dialogue between their life trajectory and literary work, the question arises, how the mapuche women writers create their subjectivity process? From their life narratives, it is considered that, through literary creation, they express ways of life against imposed identities, that are social, racial, ethnical and about gender. The objective is to reflect about the construction of their subjectivity through the craft of writing about herself. The analyses aimed to the experiences and trajectories about Mapuche women can contribute with the deconstruction of colonial, racist and sexist imaginary. The narrators, women writers and poets have been recorded the struggle to Mapuche artistic expressions be recognized as literature, which excluding dynamics are seated on the roots of European colonization that appreciate the written tradition and Spanish as official language, and that excluded the indigenous people's narratives.

KEYWORDS: Mapuche women; Subjectivity; Literature.

Busca-se neste artigo refletir acerca da construção das suas subjetividades através do ofício de escrever-se. As análises voltadas para as experiências e trajetórias de mulheres Mapuche podem contribuir com a desconstrução dos imaginários coloniais, racistas e sexistas. Assim, este trabalho aspira realizar contribuições para a construção de uma epistemologia feminista e decolonial que considera as mulheres indígenas como protagonistas da produção do conhecimento a partir das suas experiências de vida. A relevância das suas experiências como fontes de conhecimento faz com que as suas trajetórias se transformem em referência para outras mulheres e para próximas gerações de poetas indígenas. Esta pesquisa visa analisar estas experiências como narrativas contra hegemônicas, já que essas trajetórias destacam-se no meio das estruturas patriarcais e coloniais, criando novas possibilidades e caminhos na constituição das subjetividades.

A eleição das autoras foi realizada a partir da publicação realizada em 2006, chamada "Hilando en la memoria: siete mujeres Mapuche", uma antologia de obras poéticas de mulheres Mapuche que têm sido relevantes para o cenário literário chileno da atualidade. No ano de 2010 foi publicada a antologia "Kumedungun/Kumewirin: Antologia poética de Mujeres Mapuche. Siglo XX - XXI" produto da pesquisa de Maribel Mora Curriao, uma das poetas que compõe este artigo. O título Kümedungun faz referência ao seu significado na língua ancestral Mapuche que quer dizer "boas palavras". Junto à Maribel Mora Curriao, as autoras Graciela Huinao e 
Rayen Kvyeh integram este trabalho. As poesias e textos literários citados neste trabalho foram mantidos na sua língua original, o Espanhol e o Mapudungun, como um modo para trazer as vozes e a escrita das poetas da forma mais próxima à original possível.

A partir de diversos relatos que seguem, uma narrativa similar se identifica, tendo em vista que o vínculo com o território é constituinte da dimensão ontológica do Che, do ser mapuche. $\mathrm{O}$ elemento territorial está composto por planos materiais e imateriais, sejam forças ou espíritos que realizam uma mediação entre os seres humanos e a natureza. José Millalén (2006) descreve que esses referentes sobre um passado comum têm sido construídos através das relações entre diversas comunidades e as suas práticas sociais, religiosas, econômicas e políticas.

Esse território ancestral é identificado pelos Mapuche como Wallmapu, cuja localização é ao sul dos territórios atuais do Chile e Argentina, separados pela Cordilheira dos Andes. Segundo a organização ancestral, o Wallmapu estava formado pelo Ngulu Mapu (atual sul do Chile), Puwel Mapu (sul da Argentina), divididas pela Inapire Mapu (Cordilheira dos Andes); configurando-se uma unidade territorial através de relações e intercâmbios comerciais (MILLALÉN, 2006). A partir da descrição do território ancestral Mapuche são introduzidas as trajetórias das poetas, devido à relevância destes aspectos em suas narrativas.

\section{Sobre o exílio e o retorno: A trajetória de Rayen Kvyeh.}

Rayen Kvyeh é ativista política e cultural, dramaturga de formação e poeta. Realiza as publicações das suas obras de forma autônoma e divulga o seu trabalho através da casa de cultura Mapu Ñuke, localizada na cidade de Temuco, no Chile. Rayen começou sua formação artística na área do teatro, sendo interrompida pela ditadura militar, período em que foi presa política e exilada na Alemanha. Foi nesse local que começou a sua criação literária, redescobrindo a sua identidade Mapuche e tentando reconstruí-la ainda estando longe do seu território. Retorna ao Chile na década de 80 fazendo parte de uma geração de artistas que produzem obras literárias de cunho político. Atualmente dedica-se à divulgação do seu novo livro "PAZificación del Wallmapu" (2017) ${ }^{2}$.

A escritora nasceu na cidade de Huequén, na Región de La Araucanía, Sul do Chile. Ela decidiu se outorgar o nome Rayen Kvyeh - que significa Flor de Lua na língua ancestral dos

\footnotetext{
2 O livro "PAZificación del Wallmapu" faz referência ao processo histórico denominado pela história colonial como "Pacificación de la Araucanía" (1860 - 1883) no qual, após sucessivas guerras, o exército chileno conseguiu anexar o território ancestral Mapuche ao Estado-Nação Chileno.
} 
mapuche, o Mapudungun - como uma forma de valorizar e revitalizar a língua do seu povo, num contexto de discriminação pelo seu uso nas escolas. Iniciou a carreira artística como dramaturga. Em 1970 dedicava-se à produção de obras para o "Taller Experimental de Teatro" na Universidade de Concepción. Posteriormente, "(...) esteve em prisão, em 1981, durante a ditadura militar de Augusto Pinochet ${ }^{3}$. Foi desaparecida por quarenta noites e torturada no cárcere de castigo de Talcahuano. Teve que viajar como refugiada a Alemanha e Nicarágua entre 1981 e 1987" (SÁNCHEZ, 2015. p. 24). Nas palavras de Rayen:

Yo soy dramatuga también. Entonces he escrito muchas obras de teatro, y fui prisionera política porque en el tiempo de la dictadura estaba prohibido escribir teatro, y yo escribía teatro contra la dictadura. O sea, no contra la dictadura, pero es que era un teatro político, digamos, que revelaba lo que estaba pasando. Y eso me costó bastante caro. Fui prisionera política. Yo nunca he militado en un partido, por lo que escribo. Tengo mis ideas, por supuesto. Y bueno, ahí salí al exilio en Alemania. Estuve en Fraigbur, exiliada. Y después me fui a Nicaragua. ${ }^{4}$

Foi durante o período em prisão e posterior exílio que surge o processo criativo de escrever poesia "(...) como um mar incontrolável, foram águas que transbordaram dentro da cela e que se escaparam através dos orifícios das grades" (SANCHEZ, 2015, p. 26) ${ }^{5}$. A autora relata

En la noche, yo ponía mis libros sobre la cama, los libros que me llevaban de regalo, hacía una escalera con los libros, arriba de la celda. Yo estaba en una celda sola, había una pequeñita ventana, y ahí yo esperaba el momento en que la luna llegaba en la posición en la que estaba yo esperándola. Ahí empecé a conversar con la luna y aprendí que era posible iluminar mi encierro con su luz. Así empecé a escribir poesía por primera vez, porque yo escribía mucho ensayo antes, crónicas y obras de teatro, pero la poesía nació ahí (SANCHEZ, 2015, p. 26).

\footnotetext{
${ }^{3}$ Ditadura militar chilena (1973-1989) liderada por Augusto Pinochet no comando da Junta Militar. Foi imposto o terrorismo de Estado, criminalização dos movimentos sociais e sindicais através de torturas, prisão e desaparecimento de civis. No caso do povo mapuche, pessoas envolvidas no processo de Reforma Agrária (1970) foram presas e torturadas. Na região da Araucania contabilizam-se 177 casos, dos quais o $28 \%$ correspondem a prisioneiros mapuche (PICHINAO, 2015).

${ }^{4}$ Entrevista concedida na sua residência, em Temuco, Chile, no día 27 de Dezembro de 2017.

${ }^{5}$ Tradução própria.
}

Jangada | nr. 14, jul/dez, 2019 | ISSN 2317-4722 
Nesse contexto Rayen escreveu o poema "Abuela Luna":

Abuela Luna

Mi celda tiene cuatro metros cuadrados con muros de color café.

El interruptor de la luz se enciende desde afuera.

Con la caída del sol cada tarde

la carcelera la apaga.

En la parte superior de la pared del fondo hay una pequeña ventana con barrotes de fierro negro.

Una colchoneta delgada me sirve de cama y por cobija la vieja manta que me regalara mi padre.

Mis libros yacen en una desordenada algarabía.

Cada noche, con ellos construyo una montaña gasta alcanzar la ventana.

Noche tras noche llega mi abuela luna. Conversamos y compartimos la oscuridad de la prisión y la angustia de tener hijos pequeños en la vieja casa de la población. Ella... me escucha en silencio.

Mis hijos duermen.

Una luz misteriosa ilumina la humilde vivienda. Sonriente, mi abuela luna, les besa.

Por la mañana mis libros yacen en una desordenada algarabía. Los esbirros no han logrado apagar la luz de la luna.

(RAYEN KVYEH, 2011, p. 6) 
Atualmente, Rayen encontra-se num processo de produção e divulgação do seu último livro chamado "PAZificación del Wallmapu" (2017), no qual narra, através da sua poesia, os casos de julgamentos pela Lei Antiterrorista ${ }^{6}$ na região de La Araucanía, no sul do Chile, cujos principais atingidos têm sido jovens e mulheres Mapuche criminalizados pelas lutas do seu povo. Rayen assistiu aos julgamentos durante dez anos, participando ativamente das atividades de apoio aos familiares dos afetados, que vinham de regiões rurais, muitas vezes com poucos recursos.

\section{Graciela Huinao e a recuperação da memória ancestral.}

Graciela Huinao é uma escritora Mapuche-Huilliche, oriunda da zona da cordilheira do Sul do Chile. Tem sido reconhecida por ser a primeira mulher indígena a ingressar na Academia Chilena de Letras no ano de 2014, em razão da sua vasta obra e relevância no campo das Letras e da Educação Intercultural. Atualmente dedica-se à produção literária e realiza oficinas sobre cultura Mapuche em escolas e bibliotecas públicas nas periferias de Santiago.

Destacam-se as vozes femininas na obra de Graciela Huinao que fala sobre a luta por registrar a memória das mulheres. Em "Desde el fogón de una casa de putas Williche" (2010), Graciela Huinao recupera a existência das prostitutas na cultura Mapuche, situadas no contexto do surgimento dos fenômenos de urbanização, onde os habitantes do território ancestral tinham sido deslocados e deviam conviver com os winkas $^{7}$ e outros colonos europeus. Sobre suas motivações na hora de escrever, Graciela Huinao comenta que "(...) Estas mulheres sempre tem existido, não apenas na sociedade Mapuche, milhares de anos atrás. Elas tinham algo a dizer, tinham algo para contar. Se eu não o contava, iriam morrer" 8 .

Essa história começa a ser narrada a partir do ponto de vista do território, que descreve como eram as dinâmicas entre pertencimento étnico e classe social:

Esta querencia tiene por nombre Rawe y para que no digan que nació wacho ${ }^{9}$, le pusieron un apellido: 'bajo'. Rawe bajo es la cuna de los williche-lakfenche;

\footnotetext{
${ }^{6}$ A Lei Antiterrorista criminaliza o protesto social, principalmente a realizada pelo movimento mapuche e associados. Outorga sanções penais à atos como incêndios, sequestros, invasão de propriedade privada, entre outros. Porém a justiça chilena tem aplicado esta lei apenas a integrantes do movimento mapuche. Disponível em: https://www.bbc.com/mundo/noticias/2014/08/140801 chile ley antiterrorista nc . Acessado em 30/12/2017.

${ }^{7}$ Winka: Estrangeiro.

${ }^{8}$ Entrevista de rádio no programa 'Vuelan las plumas'. Tradução própria. Março de 2016. Disponível em: https://soundcloud.com/vuelan-las-plumas/graciela-huinao-23-03-2016

${ }^{9}$ Wacho: Órfão.
}

Jangada | nr. 14, jul/dez, 2019 | ISSN 2317-4722 
otrora agricultores y pescadores, hoy obreros en la ciudad. Sus manos dieron relieve al barrio que poblaron y para sobrevivir, al otro lado del río construyeron mansiones que nunca habitaron (HUINAO, 2010, p. 13).

$\mathrm{Na}$ atualidade, a cidade continua se diferenciando de acordo aos nomes de Rahue 'alto' e Rahue 'baixo', a propósito da composição étnica e social dos seus habitantes que antigamente foram deslocados do seu território e tiveram que migrar para os centros urbanos. $\mathrm{Na}$ apresentação do livro, Graciela Huinao afirma estar consciente da complexidade do tema proposto, já que existiam poucos antecedentes históricos sobre a prostituição na sociedade Mapuche-Chilena. Ela explica que "(...) em Mapudungun o conceito de compra e venda de sexo, literalmente não existe e as palavras de substituição apenas se aproximam à realidade" (HUINAO, 2010, p.9). Também expressa francamente as contradições que viveu no processo de escrita:

En complicidad con mis personajes, mediamos por la dignidad, respeto y transparencia. No niego, como mujer Williche, marcada a fuego por las religiones y escondida bajo el cinismo de los credos, estuve a punto de flaquear. Sin miedo, parecían decirme las putas cuando me tembló la mano y me puse a llorar. Y creo que el pacto se cumplió con la última letra que escribí (HUINAO, 2010, p. 8).

A partir dos conflitos colocados por Graciela Huinao, é possível interpretar que a prostituição significou uma forma de dominação colonial dos corpos das mulheres indígenas, sendo limitadas as opções para enfrentarem a pobreza e a vida precária que as cidades em ascensão lhes ofereciam. Também ilustra o confronto entre dois mundos diferentes - o indígena e o colonizador -, as suas continuidades apesar da invasão colonial, e o compromisso da autora por relatar de maneira fiel a sua memória às histórias das suas ancestrais.

Posteriormente, no seu livro "Katrilef" (2015) a autora narra a história de vida da sua bisavó Manuela Katrilef, filha de um ülmen ${ }^{10}$ Williche. Estes personagens femininos estão distantes da ideia de absoluta opressão, mas na obra "Katrilef", a autora expressa uma visão crítica acerca das estritas regras impostas sobre os corpos das mulheres Mapuche em prol da manutenção da tradição.

${ }^{10}$ Ülmen: Homem rico na sociedade Mapuche. 
Manuela Katrilef foi filha de um homem rico e de alevado status social na hierarquia Mapuche. A história se desenvolve em um contexto de guerra contra o exército chileno, que buscava anexar o território autônomo mapuche à República Chilena. Katrilef foi obrigada a casar-se com um homem que não conhecia, já que as regras do seu $A d M a p u^{11}$ indicavam que deveria se casar com quem o pai escolhesse, e participar do ritual do "sequestro", onde ela seria levada à força pelo marido e obrigada a manter relações sexuais no primeiro encontro. Se o marido demonstrasse satisfação, poderia aceitá-la como esposa, senão poderia devolvê-la à família. Ser uma mulher "devolvida" nesse contexto cultural significava completo rechaço e preconceito social (HUINAO, 2015).

Graciela Huinao relata que, no seu processo criativo, ela evoca as suas ancestrais pois sente que todas essas mulheres a compõem atualmente em espírito. Existe um sentido de responsabilidade pelo conhecimento adquirido vinculado à linhagem ancestral através da tradição oral. A autora é enfática ao afirmar que a sua maior motivação ao escrever é "(...) para que a história, os contos e os relatos orais do meu povo não morram comigo" (HUINAO, 2015, p. 3).

Ao apresentar sua obra mais atual, ela fala sobre a relevância de investigar a memória familiar e visibilizar as experiências das mulheres Mapuche que ficaram à margem da história oficial, escrita pelos winka (estrangeiros):

Creo que a mi ser femenino lo parieron con un compromiso moral, el cual consiste en testificar el casi invisible paso de las mujeres de mi pueblo en la literatura. Y no es que no hayan existido, el tiempo me ha enseñado que en todas las culturas el poderío masculino siempre ha sido más visible. (...) Ese es el motivo que me insta a forjar sus vidas, porque íntimamente las siento mujeres rebeldes y atrevidas" (HUINAO, 2015, p. 4).

\section{Vozes femininas na obra de Maribel Mora Curriao.}

A obra de Maribel Mora Curriao destaca-se por ter realizado importantes estudos que visam recuperar as obras poéticas de mulheres Mapuche nos territórios atuais do Chile e da Argentina, durante seus estudos de mestrado em Literatura. A autora organizou a publicação de duas antologias sobre a obra de diversas mulheres poetas Mapuche. Desde os cantos tradicionais

${ }^{11}$ Ad Mapu: Conjunto de leis que regem ao povo Mapuche. 
perpetuados pela tradição oral, até as obras de escritoras contemporâneas. Em 2006 foi lançada "Hilando en la memoria: 7 mujeres Mapuche" e em 2010 a antologia "Kumedungun/Kumewirin: Antologia poética de Mujeres Mapuche. Siglo XX - XXI". Atualmente ocupa o cargo de diretora da Secretaria de Equidade e Inclusão da Universidade do Chile e é doutoranda do programa de Estudos Americanos na Universidade de Santiago.

Maribel Mora Curriao nasceu na cidade de Panguipulli, Região de Los Ríos, no sul do Chile, no ano de 1970. Logo cedo sua família se mudou para a cidade de Freire, na Região de La Araucanía, onde viveu a maior parte da sua vida. É formada em Letras pela Universidad de la Frontera, em Temuco, e trabalhou como professora em Freire, até que se mudou para Santiago, - onde reside atualmente - para iniciar seus estudos de Mestrado em Literatura na Universidade do Chile.

Para pensar no encontro com a escritora e acadêmica Maribel Mora Curriao, tornam-se pertinentes as inquietações de Francesca Gargallo (2014), ao se questionar sobre a possibilidade da existência de feminismos não-ocidentais na América Latina. O não-ocidental entende-se como o pensamento que surge à margem da matriz moderna ocidental, pautada pelo colonialismo como processo que interrompeu o desenvolvimento da autonomia dos povos indígenas na América Latina. É a partir desta resistência que surgem outras formas de interpretar as relações de gênero dentro das culturas.

Maribel Mora interpela ao feminismo hegemônico, afirmando que não se identifica com uma visão de opressão absoluta das mulheres no contexto Mapuche. Reconhece que as suas referências femininas sempre têm sido de mulheres fortes e líderes familiares. A linhagem feminina forma parte do sujeito que protagoniza a sua obra "Perrimontun"12 (2014), que ela descreve como várias vozes que se expressam, mas que viveram em momentos diferentes da sua história familiar.

(...) me crié en una familia con una marcada presencia femenina también, y de mujeres fuertes. (...) Eran mujeres dedicadas a hacer muchas cosas, tenían su profesión pero además eran el apoyo de la familia. Y creo que en ese sentido el rol femenino tiene una cosa quizás en mis libros menos contestataria, menos feminista, por así decirlo. Muy de mujer, pero en mi visión, es una visión que no es feminista. Yo eso lo tengo claro. Y tiene que ver también con una historia

\footnotetext{
12 Perrimontun: Preságio.
} 
de mujeres fuertes, donde el tema del feminismo quizás no era un tema porque la mujer tenía un rol muy importante, muy relevante. ${ }^{13}$

A autora rememora a cultura feminina da sua família, construindo uma personagem composta por distintas vozes de mulheres, entendida por ela como " (...) essa ideia própria da cultura Mapuche onde você é o que é a partir de muitas pessoas que te antecederam"14

Essa entrevista reflete acerca da sua visão crítica sobre as categorias de opressão universal das mulheres, assim como a reprodução de imaginários coloniais acerca das mulheres indígenas. Para ela, certas abordagens do feminismo podem ser excludentes:

(...) ¿qué pasa con otros discursos de mujeres indígenas que no son quizás contestatarios desde ese punto de vista, sino que, al contrario, asumen un cariz maternal, de la mujer apegada a la tierra, por ejemplo? Estos discursos quedan fuera, pues es claro que se les acusa de más esencialistas, o de ocultar relaciones de dominación de género y eso les molesta a muchos. Aunque también hay otros que valoran estos discursos desde el exotismo (MORAApud FLORES, 2011, p. 159).

No início do livro "Perrimontun" (2014), evoca aos seus ancestrais, os nomeia e reconhece que a sua noção de mundo tem sido permeada desde a infância pela convivência com os avôs que transmitiram a sua história familiar. No poema intitulado "Presagios", Maribel Mora coloca a linhagem familiar como um dos sinais que procura compreender sobre a sua história e a história do seu povo.

Me habita el delirio. Encendido el corazón bajo la luna, he debido cobijarme en mi küpalme. Vacío de alma. Tierras sin espesura. Lo demás se pierde en el parpadeo de la historia. Pero los abuelos aún nos sueñan desde las montañas. Por eso escribo estas palabras. También por los hijos y los hijos de los hijos. Mañana serán del mundo...

(...) Manuela Colipe, abuela mía, madre de mis sueños. Manuel Curriao, voces oscuras, cruces de las sangres. Juan Colipe Nancuvil, Bartola Gineo, José Ignacio Chiguay, Margarita Curriao... en esas palabras-bosque aún podemos escucharlos. ¿Aún nos sueñan?, ¿Todavía las vertientes acuden a sus llamadas? He visto sus corazones pintados en las estrellas, latiendo

13 Entrevista concedida na Universidade do Chile, em Santiago de Chile, 06 de Abril de 2018. Tradução própria. 14 Entrevista concedida na Universidade do Chile, em Santiago de Chile, 06 de Abril de 2018. Tradução própria. 
inconfundibles en la corola de las flores. Si no estuvieran... Ah! si no estuvieran ¿Cómo respiraría el mundo? (MORA, 2014, p .2).

As raízes coloniais produzem dinâmicas que colocam o sujeito em lugares ambíguos, de difícil definição, uma vez que são produtos do apagamento da cultura. Por isso a autora se posiciona dentro de um processo de resgate constante da memória familiar, já que é uma das poucas fontes de história pessoal que lhe restam.

(...) El posicionamiento como Mapuche fue desde entonces un rasgo fundamental y la búsqueda ha sido atar los cabos sueltos que nos ha impedido saber/ conocer eso que fuimos como grupo humano. Buscamos aún en las bibliotecas de la República retazos de nuestra historia, que a la sazón contaban cotidianamente los weupifes $^{15}$... No conocer este pasado nos limita en nuestro conocimiento de lo que somos en este momento, de lo que podemos ser en un futuro, por eso ahondamos en la memoria, el kupan y el tuwün del origen. Sólo la reconstrucción de este entramado es lo que nos permitiría ser/ estar en el mundo como Mapuche (MORA Apud RODRÍGUEZ, 2014, p. 94).

Como Maribel Mora explica, na concepção Mapuche, os sujeitos estão constituídos por dois elementos: tüwün que faz referência ao território e, kupan ou kvpalme, que se refere à linhagem familiar. Sobre a linhagem familiar compreendemos que o sujeito está constituído pelos familiares que lhe antecederam, como a escritora ilustra em "Perrimontun", a partir da ideia de ser habitada pelos ancestrais. $\mathrm{O}$ vínculo com o território faz alusão não apenas à questão geográfica, mas também a todos os seres (não humanos) que habitam e se relacionam com a dimensão humana, incluindo elementos da natureza como montanhas, cordilheiras, vulcões, rios, mares e florestas.

\section{Abordagens sobre a escrita de si e a produção de subjetividades.}

A escrita de si configura-se como um processo ligado à produção de subjetividades. Ao referirmos ao conceito de subjetividade, Claudia Chamorro (2014) explica que os processos de subjetivação possuem relação com os posicionamentos que os indivíduos vão tomando durante as suas trajetórias a respeito das próprias experiências. Estes posicionamentos respondem a diversos fatores como contextos históricos, condições econômicas, e em definitiva, às relações

\footnotetext{
15 Weupife: Narrador.
} 
sociais.

Em concordância, Kathryn Woodward (2000) introduz de maneira conceitual as diversas interpretações sobre identidade e subjetividade, realizando algumas distinções fundamentais

\begin{abstract}
Os termos "identidade" e "subjetividade" são, às vezes, utilizados de forma intercambiável. Existe, na verdade, uma considerável sobreposição entre os dois. "Subjetividade" sugere a compreensão que temos sobre o nosso eu. O termo envolve os pensamentos e as emoções conscientes e inconscientes que constituem nossas concepções sobre "quem nós somos". A subjetividade envolve nossos sentimentos e pensamentos mais pessoais. Entretanto, nós vivemos nossa subjetividade em um contexto social no qual a linguagem e a cultura dão significado à experiência que temos de nós mesmos e no qual nós adotamos uma identidade. (...) As posições que assumimos e com as quais nos identificamos constituem nossas identidades. (...) O conceito de subjetividade permite uma exploração dos sentimentos que estão envolvidos no processo de produção da identidade e do investimento pessoal que fazemos em posições específicas de identidade (WOODWARD, 2000, p. 55).
\end{abstract}

Para falar sobre subjetividade, é indispensável remeter-se aos estudos realizados por Michel Foucault (1992), desenvolvendo uma vasta obra a respeito das práticas de si, as quais podem ser entendidas como procedimentos que contribuem a determinar, manter ou transformar a identidade com algum fim específico a partir do conhecimento ou domínio de si.

Margareth McLaren (2016) argumenta que as práticas de si obedecem ao seu contexto histórico e possuem repercussões sociais, já que implicam na transformação do indivíduo.

As políticas do corpo e as práticas de si não começam e terminam com o indivíduo. Elas são sociais, culturais e históricas. Reconhecer técnicas de si como políticas não reduz a política ao pessoal ou impede a ação coletiva ou mudança estrutural. Ao contrário, amplia a arena política, para incluir fatores sociais e culturais que têm implicações também políticas (McLAREN, 2016, p. 191).

No marco das estéticas da existência, diversas técnicas são analisadas por Foucault (1992) sobre a cultura greco-romana durante os dois primeiros séculos do Império, tais como anotações, registro de experiências espirituais, correspondências, meditações e livros da vida, 
constatando que as práticas de si visavam a construção de um sujeito ético. A tradição da escrita estava relacionada com a preservação do já dito e da prática citacional:

A escrita como exercício pessoal praticado por si e para si é uma arte da verdade contrastiva, ou mais precisamente uma maneira reflectida de combinar a autoridade tradicional da coisa já dita com a singularidade da verdade que nela se afirma e a particularidade das circunstâncias que determinam o seu uso (FOUCAULT, 1992, p. 131).

Destaca-se também que em todas as culturas é possível encontrar práticas de si ou do cuidado de si mesmo com fins de transformação social.

Estas práticas podem ser encontradas em todas as culturas, mas são histórica e culturalmente específicas. (...) As práticas de si visam a transformação. Nossos autoentendimentos e identidades sempre se desenvolvem em contextos culturais e históricos, por isso a transformação de si implica uma crítica de condições e normas sociais históricas, bem como atuais (McLAREN, 2016, p. 198).

No caso das mulheres citadas nesta pesquisa, elas se identificam com o trabalho de escritoras e porta-vozes das experiências e histórias do povo Mapuche. A modo de exemplo, Graciela Huinao comenta que a publicação das obras "Desde el Fogón de una casa de putas williche" (2010), protagonizada por prostitutas, e "Katrilef" (2015) não ficaram isentas de críticas e questionamentos. Mas para autora era relevante que essas histórias fossem contadas de maneira aberta, apesar da rejeição e o incômodo que pudessem provocar na sociedade chilena e Mapuche.

Destaca-se a afirmação da poeta Rayen Kvyeh quem considera que seu livro "PAZificación del Wallmapu" (2017) possui um caráter político, já que denuncia as injustiças que o povo Mapuche vive. Da mesma maneira, Maribel Mora Curriao considera que as múltiplas identidades que a atravessam se politizam, uma vez que ela ingressa ao meio acadêmico enquanto poeta Mapuche.

$\mathrm{Na}$ trajetória de Graciela Huinao é possível identificar momentos determinantes na construção da subjetividade, por exemplo, em relação a assumir os seus escritos como poesia e não apenas como rascunhos -, assim como o processo que a levou a se afirmar enquanto 
escritora, abrindo possibilidades para dedicar-se exclusivamente à produção literária no futuro. O seu relato traz vários elementos destacáveis como a ideia de um destino determinado pela segregação social à raiz da sua origem étnica e aos desafios de ser a primeira mulher Mapuche a trilhar um caminho voltado à criação literária.

Cuando era niña yo decía que escribía un poema, pero no tenía idea lo que eso era. Ya de grande, no me atrevía a decir que lo que escribía era poesía, o estaba catalogado dentro de una determinada cultura, porque uno viene con ese complejo de que uno era Mapuche, y que para lo único que servía era para estar trabajando en una casa de barrio alto, y eso era lo que hasta esa fecha hacían las mujeres de mi pueblo que se venían a trabajar a Santiago en el barrio alto, como lo hice yo al principio.

En ese momento, me costaba decir que lo que estaba haciendo era poesía; alguien me lo dijo y me atreví a publicarla, y con la suerte que a alguien le gustó. Fue la madre de la dueña de la casa donde yo trabajaba, quien me pidió si podía ver lo que yo escribía en cuadernito. Me dijo: 'Graciela, esto es un poema y me gusta mucho como usted escribe'. Así que ahí me motivó que a una persona educada le gustara lo que yo venía haciendo. Mandé un poema a un diario que se reparte en el barrio alto, y en vez de demorarse los dos o tres meses que me dijeron se demoraban en salir, al mes llega la dueña de la casa y me entrega un regalo. Yo lo guardé pensando que era un chocolate, pero en la noche lo revisé y casi me voy de espalda, era mi poema, que había sido publicado y ella me lo había enmarcado. El año 1987 publiqué "La Loika" y de ahí en adelante comencé a publicar; no paré más (HUINAO Apud ANDAUR, 2012, p. 143)

Graciela trabalhou como empregada doméstica nos bairros abastados de Santiago, já que seu salário seria melhor do que recebia trabalhando como secretária. Em 1989 consegue realizar sua primeira publicação chamada 'La Loika'. Assim, ela transitaria pelos mesmos caminhos de tantas outras mulheres Mapuche que migraram para a capital para trabalhar como empregadas domésticas, mas, posteriormente, com a possibilidade de uma grande reviravolta: dedicar-se exclusivamente ao seu trabalho como escritora.

Sobre a experiência migratória de Graciela Huinao ela retrata no seu poema "Simulacro de Biografia":

(...) A puerta cerrada me encontró la adolescencia. Donde el sol, al entibiar mi casa, por las ventanas asomaba un aroma a bosque en flor. Pero un día, del 
año 77, el norte se divisaba negro y cayó como quién dice del cielo. Entró en mi casa, por la puerta que más duele y cuando se le hizo pequeña mi casa, salió a las calles donde yo arrancaba dejando de par en par las puertas abiertas de mi ciudad, por la razón más desbocada que persigue a todo animal: El hambre.

Después de tanta miseria y antes que se le apolille el terno de salida, mi padre se peleó con la vida, no se defendió. Llevó su sombrero café para que la compañera de infancia lo reconociera y un ramo de flores blancas por los ocho años de espera. Sé que juntos me miran cuando escribo algún poema.

Ahora, por la esquina de mi vida el tiempo pasa severo, en un barrio marginal de Santiago y todos los días echo a cuestas mis raíces mientras mis ojos acarician la distancia entre yo y mi amante que no he podido dejar ni olvidar: EL SUR. (HUINAO. 2009, p. 14)

Neste fragmento, observa-se que diante da morte dos pais e da falta de condições de sobrevivência, a migração para os centros urbanos apresentou-se como uma possibilidade. Também o vínculo com o território de origem apresenta-se como um lugar de apego, afetividade e de memória familiar. Em definitiva, quando ela diz "(...) todos los días echo a cuestas mis raíces" realiza um exercício constante de identificação com "o sul" como seu lugar de afeto no mundo.

O desenraizamento é um sentimento constante na vida de Maribel Mora, quem assume a sua condição de migrante na construção das personagens em sua obra, e na própria trajetória de vida. Em entrevista, ela relata a história do êxodo da sua família, que passou por diversos lugares até se estabelecer na cidade de Freire, a poucos quilômetros de Temuco, capital da região de La Araucanía. No poema "Malos sueños/Weza Pewma" (2014) ela conta parte da travessia dos seus antepassados.

Con la marca de los despreciados o los elegidos, que para el caso da igual, crecí bajo el designio de mi sangre. Mi abuelo, Manuel Curriao, me acogió en su casa y vertió en mi espíritu el tormento de las estirpes que luchan ferozmente por no extinguirse.

Su madre, Margarita, se vio alejada tempranamente de las tierras del Pehuén. Con los hijos vivos a cuestas y a cargo de un patrón de fundo, emprendió el éxodo hacia La Frontera. "Dormíamos sobre la viruta de la madera, en una bodega, cubiertos con unos sacos...", dice mi abuelo y se le llenan sus ojos de 
recuerdos. Yo evoco con ternura los relatos que de niños nos prodigiaba a mí y a mis hermanos, mientras curtía y cortaba cuero para la confección de riendas que le encargaban de fundos vecinos.

$\mathrm{Su}$ recuerdo pehuenche inundó mi infancia. Desfilaban ante mis ojos los personajes de sus cuentos: vilu, ñirre, pangui, a diestra y siniestra vocablos del mapudungun, su lengua que precariamente nos entregaba.

(...)Mucha vida ha pasado ya por sus manos, pero la soledad de las montañas se ha negado a abandonarlo.

Nieve y fuego han sido sus pasos por estos alejados valles. (MORA. 2014, p. $38)$.

A escrita de si faz parte da tradição escrita como forma de registrar a história, mas os processos de subjetivação apresentam-se de maneiras diversas quando nas culturas indígenas os registros do passado são possíveis a partir da tradução oral. Nesse sentido, considerando as escritoras Mapuche, um dos limites da escrita de si apresenta-se como uma prática ligada a uma imposição institucional, e em seus relatos estão presentes os elementos da oralidade como fonte principal de recuperação da ancestralidade.

Para complementar essa intersecção entre escrita e oralidade o conceito de Escrevivência, - acunhado pela escritora Conceição Evaristo - abre uma série de possibilidades ao registro escrito, apresentando o gesto, a fala e as situações cotidianas como a origem da escrita das mulheres, cujas trajetórias são atravessadas pelos marcadores coloniais de gênero, raça, etnia e classe social. Ela relata que a sua potência criativa da escrita surge a partir do convívio com outras mulheres, vem como a necessidade de relatar as suas histórias:

Talvez o primeiro sinal gráfico, que me foi apresentado como escrita, tenha vindo de um gesto antigo de minha mãe. Ancestral, quem sabe? Pois de quem ela teria herdado aquele ensinamento, a não ser dos seus, os mais antigos ainda? (EVARISTO, 2007, p. 16);

Processos criativos vinculados à tradição oral não necessariamente possuem relação com o conhecimento institucionalizado e formal. A potência criativa das mulheres que escrevem, neste caso, mulheres Mapuche, possuem relação com as experiências vinculadas à tradição oral, ao convívio com os saberes tradicionais que permaneceram através das gerações.

É preciso comprometer a vida com a escrita ou é o inverso?, comprometer a escrita com a vida? (...) Creio que a gênese da minha escrita está no acúmulo 
de tudo que ouvi na minha infância. O acúmulo das palavras, das histórias que habitavam em nossa casa e adjacências (EVARISTO, 2007, p. 16).

A escritora chicana Glória Anzaldúa afirma "(...) eles mentiram, não existe separação entre vida e escrita" (p. 233). Em Falando em línguas: Uma carta para as mulheres do terceiro mundo (2000[1981]) a autora aborda a importância de que as mulheres excluídas criem novas narrativas sobre si mesmas, afirmando que a sua motivação é reescrever as histórias mal contadas. Apesar das dificuldades, escrever tornou-se um aspecto constitutivo da sua identidade.

Escrever é perigoso porque temos medo do que a escrita revela: os medos, as raivas, a força de uma mulher sob uma opressão tripla ou quádrupla. Porém neste ato reside nossa sobrevivência, porque uma mulher que escreve tem poder. E uma mulher com poder é temida (ANZALDÚA, Op. Cit. p. 234).

A escrita de si de Gloria Anzaldúa expressa novas possibilidades de formas de vida, trajetórias dissidentes diante das imagens controladoras projetadas sobre as mulheres mestiças, migrantes, indígenas e chicanas. As narrativas do eu procuram desestabilizar identidades fixas e as tornam complexas e dinâmicas.

Como foi que me atrevi a tornar-me escritora enquanto me agachava nas plantações de tomate, curvando-me sob o sol escaldante, entorpecida numa letargia animal pelo calor, mãos inchadas e calejadas, inadequadas para segurar a pena? Como é difícil para nós pensar que podemos escolher tornarnos escritoras, muito mais sentir e acreditar que podemos! (ANZALDÚA, Op. Cit. p. 230).

Ao analisar as trajetórias das escritoras Mapuche, destaca-se o processo que consiste em criar condições para dedicar a vida ao ofício de escrever, além do engajamento politico dos trabalhos realizados nas suas diversas áreas de atuação. Situadas distantes de qualquer romanticismo: Quem ousaria hoje viver e se dedicar completamente à escrita, à difusão, à preservação da cultura Mapuche através da arte?

A escrita de si de mulheres indígenas permite repensar as categorias utilizadas para definir gênero, assim como a adesão ao feminismo como categoria política. A perspectiva das 
mulheres indígenas diferencia-se do feminismo hegemônico, centrado no ideal do indivíduo branco, com referências coloniais, institucionalizado e liberal, pois no centro das suas práticas emancipatórias encontra-se a comunidade, junto com ela o território, e a luta pela autodeterminação. O feminismo hegemônico é interpelado pelas experiências das mulheres indígenas que lutam pelo fim da violência dos Estados e das iniciativas privadas transnacionais contra suas comunidades, já que, para além dos limites institucionais, também apostam pelas transformações estruturais. Em concordância com Karina Bidaseca (2011)

Uno de los límites que presenta el feminismo hegemónico como discurso emancipatorio es que, por un lado, separa a las mujeres de la lucha de sus pueblos, y por otro, al enfatizar el derecho a la igualdad se descuida la intersección de la clase y la etnicidad, además del género y el sexo (BIDASECA, 2011, p. 373).

Os temas abordados pelas escritoras Mapuche são múltiplos e diversos, alguns aproximam-se do resgate da tradição e da cultura, e outras expressam-se contestando as imagens controladoras que têm se construído a respeito do universo indígena. Assim, a escrita contribui à desestabilização dos imaginários coloniais que promovem ideias monolíticas acerca das mulheres indígenas.

Para finalizar, destaca-se a importância de recuperar as narrativas das mulheres dos povos indígenas para interpelar aos feminismos, e assim, construir novos saberes que transformem a matriz colonial do conhecimento que respeite os processos de emancipação das mulheres indígenas sem tentar encaixá-los em categorias preestabelecidas. $\mathrm{O}$ feminismo hegemônico precisa questionar a sua retórica salvacionista em relação às mulheres indígenas ou do Sul Global, e repensar as suas dinâmicas de emancipação focadas no indivíduo. É urgente construir conhecimentos baseados na autonomia das mulheres, desde os seus territórios e culturas, assim como é necessário que os feminismos estejam fundamentados nas lutas antiracistas, anti-coloniais e anti-capitalistas com o fim de recuperar o seu potencial de transformação.

\section{REFERÊNCIAS BIBLIOGRÁFICAS}

ANDAUR, Rafael. Poesía mapuche contemporánea: Identidad y resistencia política desde la ciudad. Dissertação de Mestrado em Comunicação Política. Santiago de Chile. Universidad de Chile. 2012. 
ANZALDÚA, Gloria. Falando em línguas: uma carta para as mulheres escritoras do terceiro mundo. In: Revista Estudos Feministas. Florianópolis, v. 8, n. 1, p. 229-236, jan. 2000.

BIDASECA, Karina. Feminismo e indigenismo. Puente, lengua y memoria en las voces de las mujeres indígenas del sur. In: Feminismos y pos-colonialidad: Descolonizando el feminismo desde y en América Latina. Buenos Aires: Ediciones Godot Argentina, 2011.

CHAMORRO, Claudia. Subjetividad y desplazamiento: las poetas mayas yucatecas y las poetas mapuches en el contexto de la reciente visibilización de las literaturas indígenas en america latina (1990-2013). Tese de Doutorado. Tese de doutorado em Estudos LatinoAmericanos. Universidad Nacional Autónoma de México. Ciudad de México, 2014.

EVARISTO, Conceição. Da grafia-desenho de minha mãe, um dos lugares de nascimento de minha escrita. In: ALEXANDRE, Marcos Antônio (Org.). Representações performáticas brasileiras: teorias, práticas e suas interfaces. Belo Horizonte: Mazza Edições, 2007. p. 1621.

FOUCAULT, Michel. A coragem da verdade: O governo de si e dos outros II. Curso no Collège de France (1983-1984). São Paulo: Martins Fontes, 2011.

. A escrita de si. In: O que é um autor? Lisboa: Passagens. 1992. p. 129-160.

FLORES, Fabián. Entrevista a Maribel Mora Curriao. In: Revista ISEES. Santiago de Chile. n. 9. 2011. p. 155-167. Disponível em: https://dialnet.unirioja.es/descarga/articulo/3777540.pdf Acesso em abril 2018.

GARGALLO, Francesca. Feminismos desde Abya Yala: ideas y proposiciones de las mujeres de 607 pueblos en nuestra América. Bogotá: Ediciones Desde Abajo, 2015.

HUINAO, Graciela. Walinto. Santiago de Chile: Editorial Cuarto Propio, 2009.

. Desde el fogón de una casa de putas Williche. Osorno: Ediciones caballo de mar,

2010.

. Katrilef: Hija de un ülmen Mapuche. Relato de su vida. Santiago de Chile, 2015.

MILLALÉN, J; MARIMÁN, P; CANIUQUEO, S. i...Escucha, winka...! Cuatro ensayos de historia nacional Mapuche y un epílogo sobre el futuro. Santiago de Chile: Ediciones LOM, 2006.

McLAREN, Margareth. Foucault Feminismo e Subjetividade. São Paulo: Intermeios, 2016.

MORA CURRIAO, Maribel. et al. Hilando en la memoria. 7 mujeres Mapuche. Santiago de Chile: Editorial Cuarto Propio, 2006.

MORA CURRIAO, Maribel. Kümedungun/Kümewirin: Antologia poética de mujeres mapuche (siglos XX-XXI). Santiago de Chile: Ediciones LOM. 2010.

. Perrimontun. Santiago de Chile: Editorial Konünwenu, 2014.

. Poesía Mapuche del siglo xx: escribir desde los márgenes del campo literario. In: $T a$

iñ fijke xipa rakizuameluwün. Historia, colonialismo y resistencia desde el país Mapuche.

Temuco: Ediciones Comunidad de Historia Mapuche, 2012.

PICHINAO, Jimena. La mercantilización del Mapuche Mapu (tierras mapuche). Hacia la expoliación absoluta In: Awükan ka kuxankan zugu Wajmapu mew. Violencias coloniales en Wajmapu. Temuco: Ediciones Comunidad de Historia Mapuche, 2015.

RAYEN KVYEH. PAZificación del Wallmapu: El despojo en manos del Estado en el territorio mapuche. Temuco, 2017.

. Luna de las cenizas. Luna de cenizas. Temuko: Mapu Ñuke, 2011.

Jangada | nr. 14, jul/dez, 2019 | ISSN 2317-4722

139 | Pá g i n a 
RODRÍGUEZ, Elvira. El cuerpo como (pre) texto literario. In: Revista Estudios Avanzados. Santiago de Chile n. 21. 2014. p. 91-110.

SÁNCHEZ, Juan Guillermo. Los esbirros no han logrado / apagar / La luz de la luna: Rayen Kvyeh. In: Revista Maguaré. Bogotá, v. 29, n. 1. 2015, p. 21-53.

WOODWARD, Kathryn. Identidade e diferença: Uma introdução teórica e conceitual. In: DA SILVA, Tomaz (org.). Identidade e diferença: a perspectiva dos estudos culturais. Petrópolis: Vozes, 2000. 